\title{
Application of Modern Information Technology in Sci-tech Journal Editing and Publishing Process
}

\author{
Lihua Zhao \\ Editorial Department of Journal \\ Jilin Agricultural University (JLAU) \\ Changchun 130118, China \\ Email: Zhaolihua2004@126.com
}

\begin{abstract}
In order to improve the editing and publishing efficiency of sci-tech journals, to realize the digitization, networking and modernization of sci-tech journal editing and publication. This paper studies the application of modern information technology in the editing and publishing of sci-tech journals by combining theory with practice. Practice has proved that the application of computer technology, network technology, the application of multimedia technology and other modern information technology has greatly improved the editing and publishing work efficiency and quality of the whole process of journal editing and publication of sci-tech journals, which is inseparable from the modern information technology. Modern information technology gives the traditional means of sci-tech journals and its editors with new vitality and connotation. It can change the traditional mode of journal editing and publication, and realize digitization, networking and modernization of editing and publication, accelerating the spread of sci-tech achievements.
\end{abstract}

Keywords-Modern information technology; Computer technology; Network technology; Multimedia technology; Sci-tech journal; Editing and publishing process

\section{INTRODUCTION}

Sci-tech journals are important carriers of scientific research achievements, but the traditional editing and publishing model and efficiency has become a serious problem restricting the development of sci-tech journals. With the development and popularization of computer, network, multimedia and other modern information technology, the editorial and publishing pattern of sci-tech journals also has changed a lot. Traditional editorial and publishing pattern can not meet the needs of development in the new situation and period, which requires the editing and publishing pattern be reformed.To improve the efficiency of sci-tech journals editing and publishing, shorten the publishing period and improve the quality of journals, we have done the research on application of modern information technology in a series of publishing process including selecting topic, soliciting contribution, reviewing, proofreading, editing, publishing and distributing by adopting the method of combining theory with practice. Practice has proved that every step of sci-tech journal editing and publishing process can be done on the Internet. The modern information technology, an important mean of sci-tech journal editorial work in the new period, can greatly improve the efficiency of journal editing and publishing, reduce the burden of editorial work, shorten the publishing period, enhance the timeliness of information, improve the quality of journals, accelerate the spread of scientific and technological achievements, and promote the internationalization of sci-tech journals.

\section{Selecting Topics, Soliciting Contributions AND REVIEWING PAPERS THROUGH MODERN INFORMATION TECHNOLOGY}

Selecting topics through modern information technology. First, websites and platforms of sci-tech journals editing and publishing need to be established and scientific and technical journal paper gathering and editorial system can be used[1][2][3][4]. Editors can know the developing direction of each subject and profession, acquire the newest scientific trend, track academic research fronts of universities or the research institutes and widen the channel of topic selection. The latest information can be acquired conveniently, timely, accurately and infinitely through online research [5]. The editors can quickly conclude, make a judgment, determine the topic, and judge whether the identified topic is novel and unique through the network to retrieve topic selection. By using network to select topics, editors can get a lot of information they need without going out, which can increase the efficiency the editing work and reduce the burden of editors.

Soliciting contributions through modern information technology. After confirmation of topic, editors can contact with authors for acquisition at any time, or collect manuscripts by sending e-mails. To make the authors' contribution targeted and initiative, the editors can introduce the principle, features, retrieval details, effects of the journal both at home and abroad as well as offer instructions for authors through the modern information technology before contributions, etc. Online soliciting contributions will be beneficial to enlarge the author group and attract more wonderful manuscripts. Before contribution, authors can inquire submission details by e-mail (or QQ), then surf university journal website, register articles through the gathering and editorial system and submit online [6]. Traditional editing and publishing mode is that editors download the manuscripts from the e-mails and register papers one by one, which is a tedious and time-consuming job. However, the manuscript management system refers the work to authors, and they need to fill in the necessary information according to the cues when submitting manuscripts through the system. The Manuscript management system can produce the basic information of the manuscripts when the authors 
complete the submission, which is automatically recorded and stored in the database, the system registers the manuscripts while they are submitted, greatly improving the work efficiency. Submission by e-mail is also allowed if there is no collecting and editorial system available.

Reviewing papers through modern information technology. When receiving manuscripts, editors need to give the paper preliminary review and check the content using academic article detecting system. If the contributions detected are unqualified or their content repetition rate is over stipulated ratio for the journal, they will be rejected to prevent the occurrence of academic misconduct from the source. If the contributions inspected are qualified and pass preliminary examination will be sent to outside review. sci-tech journals are highly professional, which determines the sci-tech journals should have a stable and efficient reviewing expert team. With the rapid development of science and technology, subject branch is becoming more and more. Therefore, updating and supplementing reviewing expert team are also needed.

Various experts research direction, degree, title, address, Email, etc. of universities and research institutes of related disciplines can be found using the Internet. Journal Editors can establish reviewing expert database using the information, update and supplement reviewing experts. Reviewing experts of sci-tech journals can $\log$ in the website, review papers through the scientific and technical journal manuscript management system online, upload the reviewing opinions, and can also review by e-mail. Online review, breaking the barriers of time and space, makes it possible for the editors to get in touch with the authors and reviewing experts quickly, and feedback to the author of manuscript processing information and provide related documents. Online review not only shortens the review period greatly, but avoids the loss of manuscripts and delay of reviewing without sending paper copy, and save the manpower and postage [7][8]. The manuscript management system provides a common platform for authors, editors and reviewers to solve the problems effectively. Through the system, the process of reviewing manuscripts can be sped up and the cycle of reviewing manuscripts can be shortened. The chief editor may distribute the reviewed manuscripts to every editor in time and grasp the distribution of manuscripts in real-time progress and how editors handle the manuscripts assigned to them. On the condition that the network is not blocked, the communication between authors, reviewers, the editorial board, editors in chief and editors can be carried out online anytime and anywhere. Whether the manuscripts are from experts or ordinary authors, the manuscript information can be more timely and accurately fed back. As long as the information can be updated in time, authors can find the processing of the manuscripts in real time.

\section{Editing, TyPesetting, PROOFREADING, PUbLishing AND DISTRIBUTING THROUGH MODERN INFORMATION TECHNOLOGY}

Editing, typesetting, proofreading through modern information technology. The development of modern information technology has made revolutionary changes of editing pattern in sci-tech journals. The traditional editing mean is gradually replaced by network technology. Using the Internet for editing, typesetting, proofreading, can not only improve the work efficiency greatly, reduce the error rate and editing work burden, but can reduce the cost of publication. It is new modern editing work mode. For example, in the editing process, when the manuscript appears unclear original figure, missing experimental data, quantity and unit problems, nonstandard use of bibliographic and references, the editor can inform the authors by e-mail, QQ or science and technology journal gathering and editing system. The authors can timely modify the papers according to these specific issues, and resubmit the revised manuscripts to the editors through the manuscript editorial system or e-mail.

Proofreading through modern information technology. Using the computer typesetting system (such as the founder typesetting software) for typesetting can greatly improve the layout efficiency and make the format design more scientific, beautiful and generous. In addition, in the editing and publishing process, proofreading is an important part to ensure the quality of the journal [9]. The speed can directly affect whether the journal can be normally published on time. There are lack of personnel and no professional proofreaders in some journal editorial office, so the editors have to carry general proofreading work, namely redaction integration. Editors edit manuscripts, and also bear the heavy proofreading task. The application of online redacting software not only greatly reduces the editors' burden of proofreading, but also increases the speed and improves the accuracy of proofreading [10].

Publishing and distributing through modern information technology. The development of modern information technology has made diverse publishing forms of sci-tech journals. Online publishing and electronic periodicals are developing rapidly, which brings serious challenges to traditional paper publication. In order to spread excellent academic achievements in a timely and effective manner, raise the value of approval, spread and utilization of the academic achievements, the papers, after outside review, finalized version and careful editing processing, can be firstly published on CNKI (China National Knowledge Infrastructure) in a digital version, namely the first digital publishing. This process enables the authors' research results confirmed in a timely manner and can also shorten the publishing time, improve the transmission speed, and attract many authors and readers. 


\section{RETRIEVING AND PROPAGANDIZING THROUGH MODERN INFORMATION TECHNOLOGY}

Retrieving through modern information technology. An important index to evaluate the academic level of sci-tech journals is the journal collection situation by authoritative retrieval system and database both at home and abroad. Modern information technology can be used to detect national and international famous retrieval systems and databases, making it easy to find the state of journal retrieved and referenced. Sci-tech journals editors should often browse some domestic and foreign relevant professional journals website according to the characteristics of the journals [11], follow other journals' publishing situation and developing trends, learn from their experience of running the journal, and find out gap and make complement.

Propagandizing sci-tech journals by using modern information technology can expand the scope of propaganda, which can help readers and the authors both at home and abroad to know sci-tech journals, and make a globalization of the authors and the readers. Propagandizing university Journals on the internet can realize two-way and multiway communication, expand and enrich the propaganda content [12], and shorten the distance between journals, readers, authors and reviewing experts. It will benefit to mobilize the potential readers and authors, enlarge subscribers, increase the circulation and expand the academic influence of sci-tech journals, improving popularity of the journals. It is a quick, intuitive and economical way to promote the journals through the web [13]. The modern information technology can make the editorial departments publish the whole papers so that readers can download the papers they need for free by browsing the websites of the editorial departments, which increases the reading quantity of the publications so as to promote academic exchange and enhance the influence of the journals[14,15,16,17].

\section{EDITORS SHOUld CHANGE THEIR IDEAS AND ACCEPT THE APPLICATION OF THE MODERN INFORMATION TECHNOLOGY}

Editors should accept the modern information technology. The traditional editing and publishing model is deeply rooted in editors for a long time. While the application of the the modern information technology brings convenience to editing and publishing, it will inevitably bring some impact to the traditional editing and publishing model. In order to make better use of the modern information technology, the editorial department needs to make a rational division of labor, overall arrangement of personnel and their specific work according to the change in the mode of work. Therefore, editors need to update awareness and change their ideas, only in this way can the functions of the modern information technology be brought into full play and work efficiency can be improved [14]. Therefore, editors of journals must renew their thinking, change their concepts, enhance their sense of the times and urgency, foster modern editing consciousness and enhance their ability to accept new things.
Editors should improve the application ability of the modern information technology. Computer, network, multimedia and other modern information technology impact on the development of university journals more and more deeply. This not only brings opportunities and challenges to the development of university journals, but also puts forward new and higher requirements for journal editors, which is an unprecedented test for editors. Moreover, this kind of test becomes urgent with the development of information technology, which requires that journal editors not only have the quality and ability in the traditional sense, but also learn modern editing theory and techniques so as to improve the modern information technology application ability continuously. This requires editors to take part in related training so that they can get familiar with and master the functions and application of the modern information technology as soon as possible. This requires editors to keep pace with the times, to improve their ability to learn independently and to continue to learn so as to replenish, update and optimize the knowledge structure in time. At present, learning has become a very important and urgent task in the implementation of talent strategy in modern publishing industry [18].

\section{CONCLUSION}

In short, modern information technology transmission has broken the limit of time and space, and is characterized by instant, efficiency, convenience and variety. It makes the scitech journals publishing form diversified, editing means modernized, and readers, authors and reviewing experts globalized.[19][20].Practice has proved that the modern information technology can transfer the real-time information between authors, reviewers, the editorial board, chief editors, editors and readers, lighten the burden of editing, greatly improve work efficiency, shorten journal publishing cycle, enhance the timeliness of information and realize the journal publishing digitization, networking and modernization. At the same time, it facilitates the authors' delivery, modification and query of the manuscripts, and improves the authors' satisfaction, which can attract more high-quality manuscripts, thus improving the quality of journals. But, the modern information technology brings the opportunity to speed up development of sci-tech journals, also proposes a serious challenge. The more fierce competition among the sci-tech journals has put forward new and higher request for editors [21] [22] [23] [24]. Therefore, sci-tech journals editors, according to the reality of the journal of service, should adapt the needs of development, make full use of the platforms provided by network, make efforts to study computer theories and operating technologies, master network technology skillfully, learn modern editing skills, improve the efficiency and overall quality of journals editing and publication, realize the digitization, networking and modernization of journals editing and publishing, and promote the internationalization of sci-tech journals. 


\section{REFERENCES}

[1] Q.H. Chen, J.L. Gao and X.N. Zhou, Thoughts on Problems of Sci-tech Periodicals Online and Online sci-tech Journals [J]. Editing Science and Technology, pp.1-3, December 2000. (In Chinese).

[2] M. Li, Application of Journal Network Gathering and Editing System [J] Computer Knowledge and Technology, Vol, 8, pp. 8332-8333, No.34 2012. (In Chinese).

[3] Y. Yang, Research on the Sci-tech Periodicals Network Purchasing \& Cataloguing System [J]. Information Science, Vol.29, pp..864-866, June 2011. (In Chinese).

[4] S. X. Zhou and L.J. Liang, Usage of the online gathering and editing system benefits sci-tech journal Network [J]. Agricultural Research and Application, pp. 75-77, June 2014. (In Chinese).

[5] J. H.Chen, Sci-tech periodical editors' information choice under network environment [J]. Acta Editologica, Vol.8, pp.306-308, April 2006. (In Chinese).

[6] Y. B. Xu, Z.Q. Yang and Y.Z. Song, Some suggestions on online submission system of sci-tech periodicals [J]. Acta Editologica, Vol. 22, pp. 260-261, March 2010. (In Chinese).

[7] W. Deng and H.L. Zhang, Processing and Management of Contributions in Sci-tech Journals: Use of Network System [J]. Journal of Wuhan University of Science and Technology (Social Science Edition), Vol.8, pp.144-145, May 2006. (In Chinese).

[8] X. Zhang, Application of Computer Network Technology in Journal Editing [J]. Journal of Yunyang Teachers College, Vol.36, pp.54-57, February 2016. (In Chinese)

[9] X.Y. Zhang, X.Z.Jiang and M.D.Li, Standardization, normalization and internationalization of sci-tech periodicals[J].Chinese Journal of Scientific and Technical Periodicals, p.740, No.14(Special Issue) 2003. (In Chinese).

[10] C.L.Guo, Application of Network Technology in Sci-tech Journa Editing [J]. Journal Editors Forum, pp.174-176, February 2008. (In Chinese).

[11] Q. Zhou, Probe on the role of Internet on achieving sci-tech journal publishing modernization [J]. Acta Editologica, Vol.12, pp. 146-147, March 2000. (In Chinese).

[12] X.H.Chen and L. Wang, Network and Journal [A]. Chinese Universities Natural Science Research Council. Proceedings of Technical Editing Science [C]. Beijing: Beijing University of Technology Press, pp. 92-95, 2001.(In Chinese).
[13] P.He, Necessity of International Development of Biological Science Journals and Its Main Way [J]. Chinese Journal of Scientific and Technical Periodicals, p.787, No.14 (Special Issue) 2003. (In Chinese).

[14] S.H.Zhang, Q.Xu and H.M. Wang: Advantages and Current Situation of Manuscript Management System[J].Hunan Journal of Traditional Chinese Medicine, Vol. 32 , pp. 211-212, July 2016. (In Chinese).

[15] Y. Yang: Research on the Sci-tech Periodicals Network Purchasing \&Cataloging System[J]. Information Science, Vol.29, pp. 864-866, June 2011. (In Chinese).

[16] T. Zeng, Current Situation and Prospect of Manuscript Managemen System [J]. Jianghan Univ. (Nat.Sci. Ed), Vol.40, pp. 101-104, April 2012. (In Chinese).

[17] W.W. Zhang, W.J. Yang, C.M. Fu and D.H. Shi: Application of Manuscript Management System [J].Education of Chinese Medicine, Vol. 31, pp. 76-77, May 2012.(In Chinese).

[18] L.C. Chang: New Exploration of Editorial Personnel Training Mode in the Era of Mass Media [J]. Journal of Tibet Nationalities Institute (Philosophy and Social Sciences), Vol. 30, pp. 101-104, April 2009. (In Chinese).

[19] H.F.Yu, L.J Yang and S.G. Zhu, Research on Editing and Publishing Science and Development Prospect in the Internet Era[J]. Editor's Friend, pp. 33-37, April 2001.(In Chinese)

[20] F.L.Song and X.L. Jiang, Opportunities Faced by Chinese Sci-tech Journals in the New Century $[\mathrm{J}]$. Chinese Journal of Scientific and Technical Periodicals, Vol.11, pp. 17-18, January 2000. (In Chinese).

[21] X.Y.Bai, Reflection on the Cultivation of College Journal Editors' quality in the New Era [J]. Journal of Chifeng University, Vol.32 pp.171-172, March 2016. (In Chinese).

[22] R.J.Yang, On Improvement of the of Editors' Quality of Journal in the Era of Network Digitalization [J]. Journal of Suzhou University of Science and Technology (Social Science), Vol.27, pp. 94-96, June 2010. No.6, (In Chinese).

[23] J.H.Wang and F. Wang, Discussion on the Culture Mechanism of Editing Personnel of Scientific Periodicals[J].Journal of Library and Information Sciences in Agriculture,Vol.18, pp. 119-121. May 2006.(In Chinese).

[24] Y. Zheng, On Qualities of the Editors and the Ways to Improve Thei Qualities in Colleges and Universities [J]. Journal of Inner Mongolia University for Nationalities (Social Sciences), Vol 39, pp. 106-109, June 2013.(In Chinese). 